\title{
Clear cell odontogenic carcinoma mimicking a cystic lesion: a case of misdiagnosis
}

\author{
Minkyu Kim¹, Eunae Cho ${ }^{2}$, Jae-Young Kim ${ }^{1}$, Hyun Sil Kim ${ }^{2,3}$, Woong Nam ${ }^{1,3}$ \\ Departments of ${ }^{1}$ Oral and Maxillofacial Surgery and ${ }^{2}$ Oral Pathology, ${ }^{3}$ Oral Cancer Research Institute, \\ College of Dentistry, Yonsei University, Seoul, Korea
}

\begin{abstract}
J Korean Assoc Oral Maxillofac Surg 2014;40:199-203)
Clear cell odontogenic carcinoma (CCOC) is a rare jaw tumor that was classified as a malignant tumor of odontogenic origin in 2005 by the World Health Organization because of its aggressive and destructive growth capacity and metastasis to the lungs and lymph nodes. We report a case of a 66-year-old female who had swelling, incision and drainage history and a well-defined unicystic radiolucent lesion that was comparable to a cystic lesion. At first, the patient received decompression, and the lesion size decreased. Three months after decompression, cyst enucleation was performed. The pathologic result indicated that the lesion was CCOC. In this report we emphasize that patients with painful cystic lesions in addition to jaw enlargement and loosening teeth should be considered for the possibility of malignancy.
\end{abstract}

Key words: Mouth neoplasms, Head and neck neoplasms

[paper submitted 2014. 4. 4 / revised 2014. 7. 10 / accepted 2014. 7. 29]

\section{Introduction}

Clear cell odontogenic carcinoma (CCOC) is a rare jaw tumor that was first described by Hansen et al. ${ }^{1}$ in 1985 , in which patients presented with local bony invasions without metastasis. At first, CCOC was called a clear cell odontogenic tumor or clear cell ameloblastoma, and was considered more aggressive than ameloblastoma. The potential for CCOC to metastasize was initially unclear; however, CCOC was defined as a benign tumor in the 1992 World Health Organization (WHO) classification ${ }^{2}$.

The WHO reclassified CCOC as a malignant tumor of odontogenic origin in $2005^{3}$ because of its aggressive and destructive growth capacity and metastasis to the lungs and

\footnotetext{
Woong Nam

Department of Oral and Maxillofacial Surgery, College of Dentistry, Yonsei University, 50 Yonsei-ro, Seodaemun-gu, Seoul 120-752, Korea

TEL: +82-2-2228-2971 FAX: +82-2-2227-8022

E-mail: omsnam@yuhs.ac

(c) This is an open-access article distributed under the terms of the Creative Commons Attribution Non-Commercial License (http://creativecommons.org/licenses/by-nc/3.0/), which permits unrestricted non-commercial use, distribution, and reproduction in any medium, provided the original work is properly cited.

Copyright (C) 2014 The Korean Association of Oral and Maxillofacial Surgeons. All
} rights reserved. lymph nodes ${ }^{4-8}$. About one-third of CCOC cases were initially misdiagnosed, and the primary diagnosis was ameloblastoma which lead to inadequate treatment for some patients. In this case report, we describe a case of a CCOC, which presented in a similar manner to a cystic lesion; the patient was misdiagnosed and received insufficient treatment. We introduce this case to discuss differential patient presentations to reduce the rate of malignancy misdiagnosis.

\section{Case Report}

A 66-year-old female visited the Department of Oral and Maxillofacial Surgery at Yonsei Dental Hospital due to swelling and pain on the right premolar maxillary area. Incision and drainage had been performed at a local clinic 5 days previously. Clinical examination showed fluctuating swelling on the right maxillary vestibule with tenderness to palpation, severe tooth mobility and loss of vitality on the first and second premolars and no appreciable cervical lymphadenopathy. A panoramic radiograph revealed an approximately $27 \times 29 \mathrm{~mm}$ well-defined radiolucency in the apex of the maxillary right premolars with root resorption. (Fig. 1) A computed tomography (CT) scan showed a low

This work was supported by the Priority Research Centers Program through the National Research Foundation of Korea (NRF) and funded by the Ministry of Education, Science and Technology (2009-0094027). 
attenuated cystic lesion with a volume of $7,419 \mathrm{~mm}^{3}$ (Simplant software; Materialise, Leuven, Belgium).(Fig. 2)

At first, the lesion was diagnosed as infected odontogenic cyst (radicular cyst), the patient received decompression in order to separate the cyst from maxillary sinus wall. A yellowish exudate was discharged from the cyst while a local anesthetic was injected. The cystic wall was too thin and

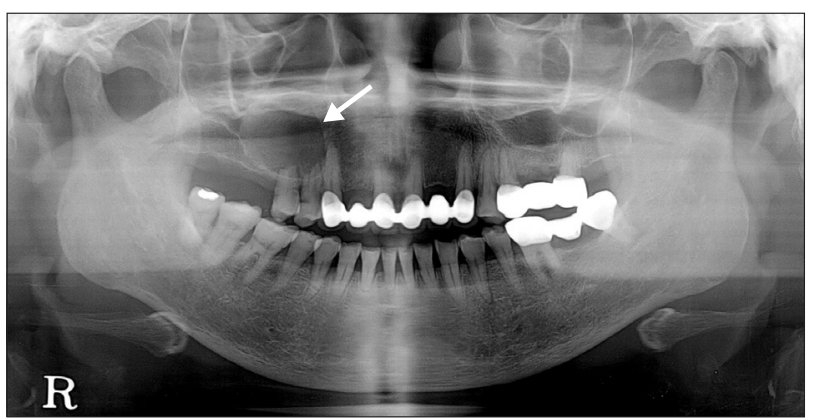

Fig. 1. Panoramic radiograph showing a defined radiolucent lesion in the right maxillary region (arrow).

Minkyu Kim et al: Clear cell odontogenic carcinoma mimicking a cystic lesion: a case of misdiagnosis. J Korean Assoc Oral Maxillofac Surg 2014 fragile to be sent for pathologic examination. Two months after decompression, a panoramic radiograph showed that the lesion size was reduced to approximately $25 \times 26 \mathrm{~mm}$.(Fig. 3) The lesion was reduced to a volume of $4,797 \mathrm{~mm}^{3}$ (Simplant software) on the 3-month follow-up cone-beam CT.(Fig. 4) The measurement and comparison may not be precise because of the differences in CT imaging; however, there was

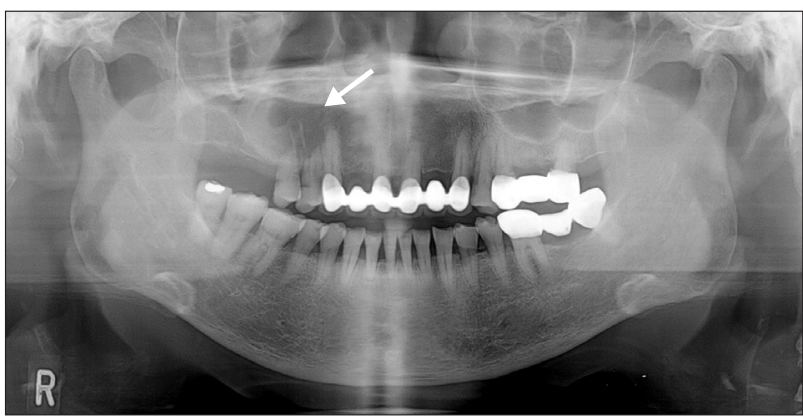

Fig. 3. Two month after decompression, a panoramic radiograph showed that a lesion size decreased, compared with previous radiograph (arrow).

Minkyu Kim et al: Clear cell odontogenic carcinoma mimicking a cystic lesion: a case of misdiagnosis. J Korean Assoc Oral Maxillofac Surg 2014
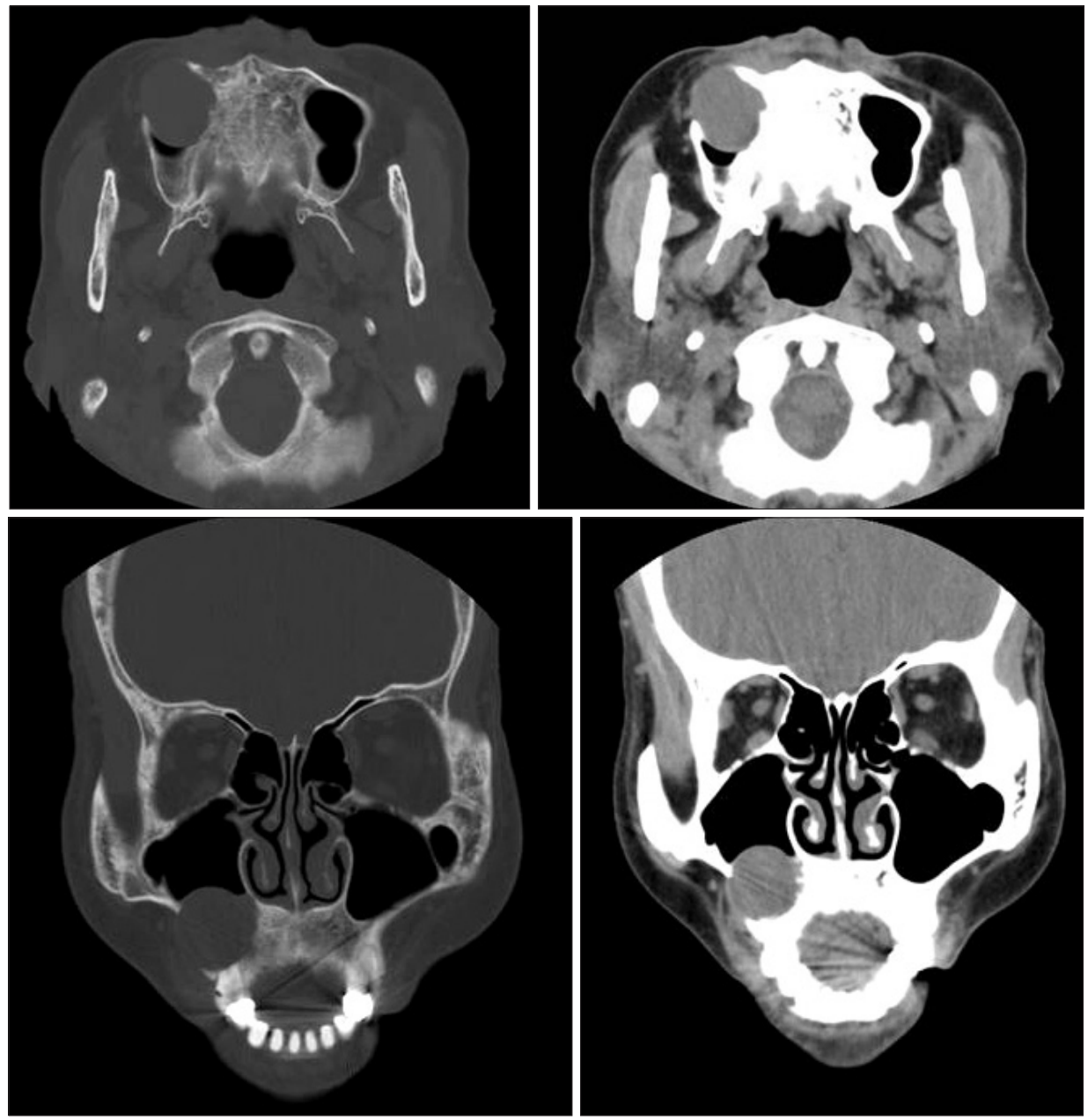

Fig. 2. Computed tomography image at first visit showed well defined and low attenuated cystic lesion on the right maxillary region.

Minkyu Kim et al: Clear cell odontogenic carcinoma mimicking a cystic lesion: a case of misdiagnosis. J Korean Assoc Oral Maxillofac Surg 2014 

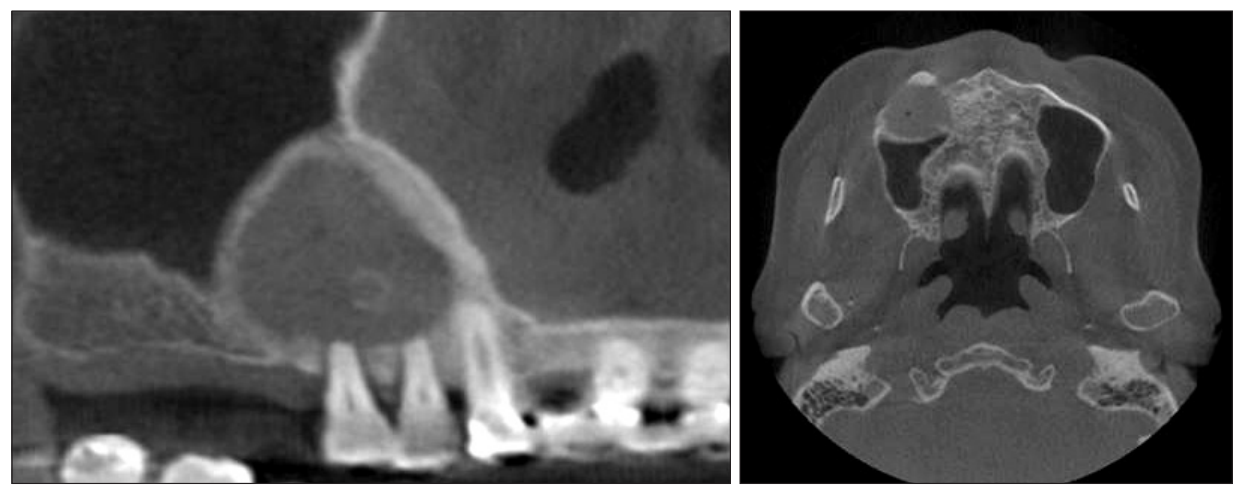

Fig. 4. Three-month follow-up conebeam computed tomography image after decompression.

Minkyu Kim et al: Clear cell odontogenic carcinoma mimicking a cystic lesion: a case of misdiagnosis. J Korean Assoc Oral Maxillofac Surg 2014
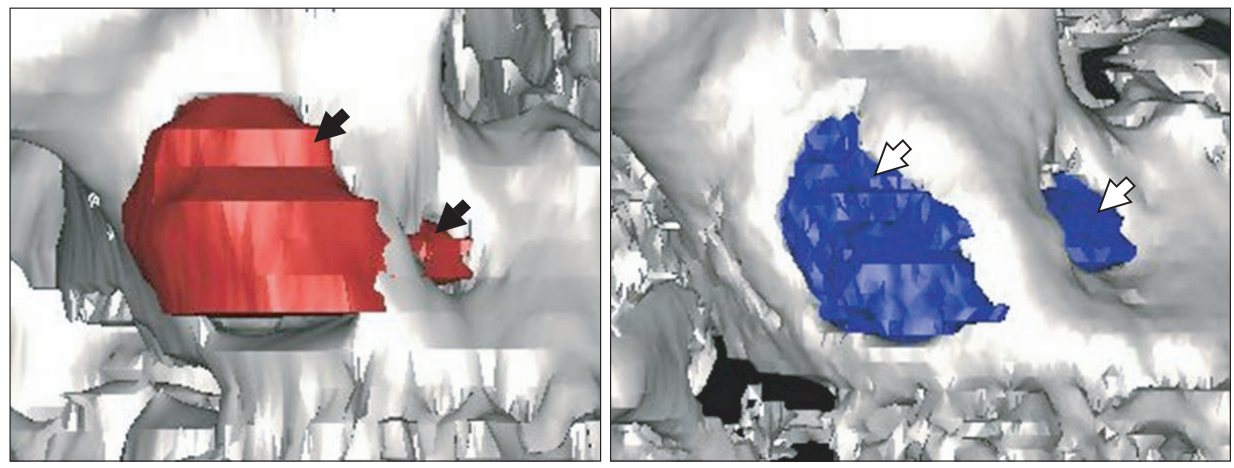

Fig. 5. Three-dimensional reconstruction image, image at first visit is on the left (lesion is indicated with black arrows) and image at 3-months after decompression is on the right (lesion is indicated with white arrows).

Minkyu Kim et al: Clear cell odontogenic carcinoma mimicking a cystic lesion: a case of misdiagnosis. J Korean Assoc Oral Maxillofac Surg 2014
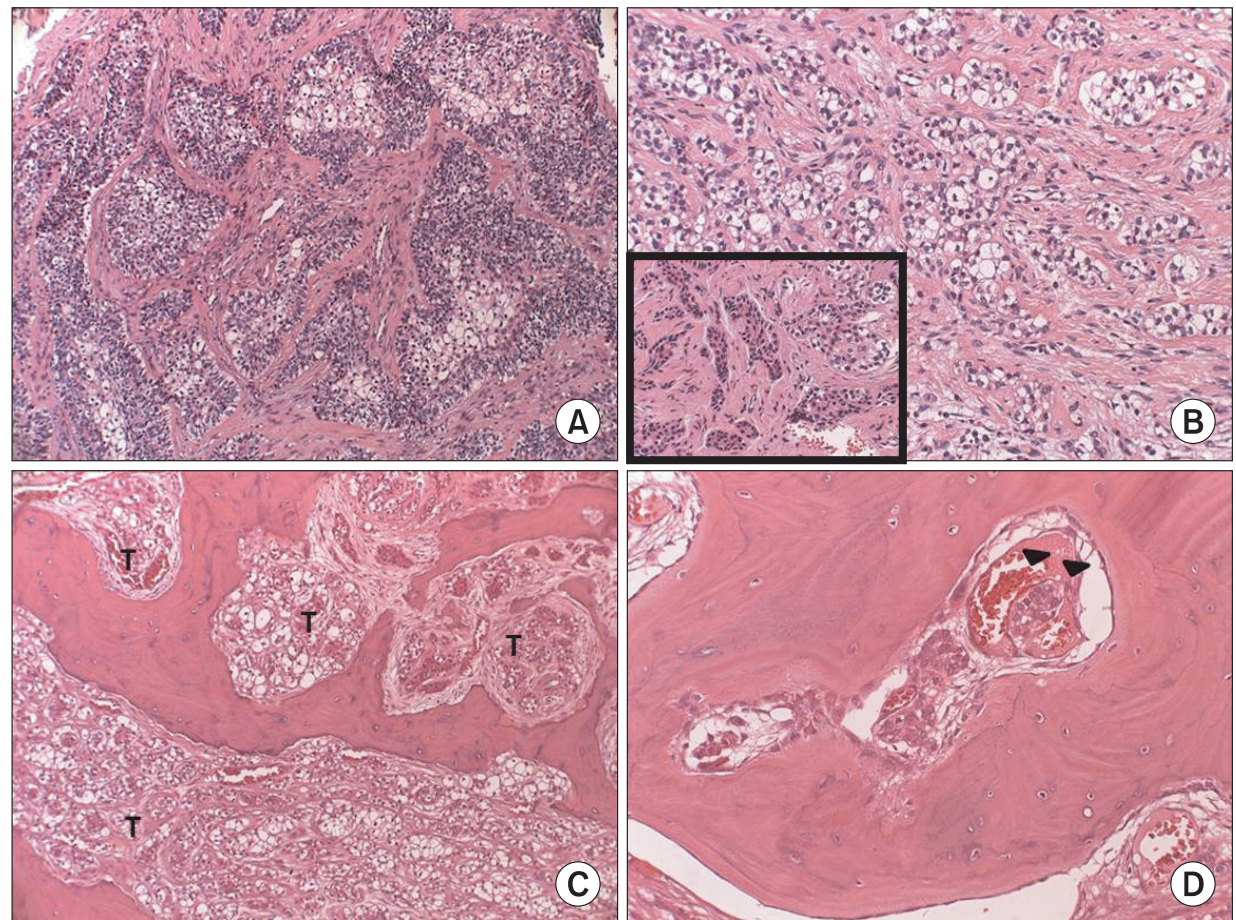

Fig. 6. Histopathologic findings. A. Histopathologic examination of the previous enucleation specimen revealed tumorous proliferation of epithelial nests infiltrating the stroma, indicating malignancy (H\&E staining, $\times 100)$. B. Cuboidal shaped odontogenic cells were also noted among the tumorous clear cells (H\&E staining, B: $\times 200$, inset box: $\times 200)$. C. In the resected specimen, the tumor cells $(T)$ infiltrated to the bone marrow of the maxilla (H\&E staining, $\times 100)$. D. Lymphovascular permeation of tumor cells (arrowheads) (H\&E staining, $\times 200$ ).

Minkyu Kim et al: Clear cell odontogenic carcinoma mimicking a cystic lesion: a case of misdiagnosis. J Korean Assoc Oral Maxillofac Surg 2014

definite shrinkage of the lesion.(Fig. 5)

Because there was not a change in the lesion size, a cyst enucleation was performed and specimens were sent to oral pathology. Unexpectedly, the pathologic results indicated that the mass was CCOC.(Fig. 6. A, 6. B) Magnetic resonance imaging of the neck and positron emission tomography CT, were taken to examine the lymph nodes and distant metastasis.(Fig. 7) There were no pathologic lymph nodes and evidence of metastasis. A partial maxillectomy was performed without neck dissection. An obturator was placed at the time 

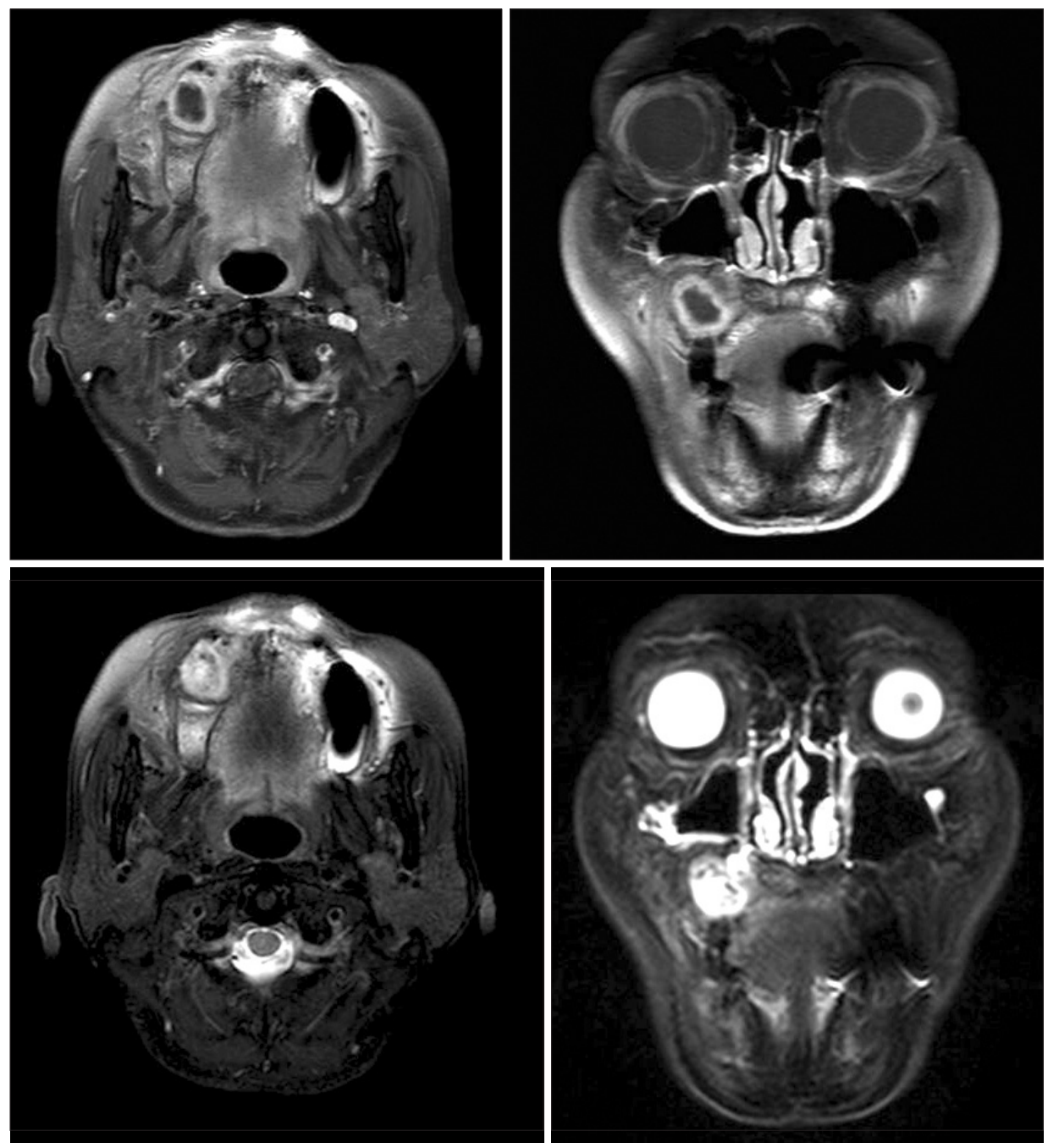

Fig. 7. Magnetic resonance imaging after enucleation of the lesion. The top image is T1-weighted and lower image is T2-weighted. Magnetic resonance images show a well-defined cystic mass.

Minkyu Kim et al: Clear cell odontogenic carcinoma mimicking a cystic lesion: a case of misdiagnosis. J Korean Assoc Oral Maxillofac Surg 2014

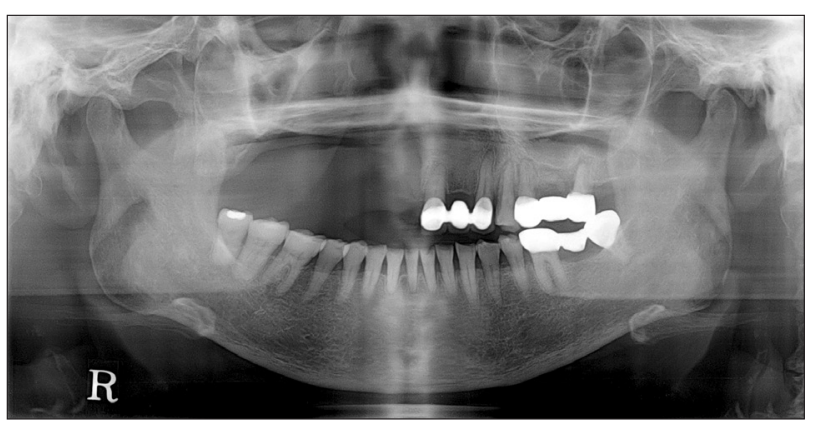

Fig. 8. There was no evidence of local recurrence on eight month follow-up panoramic radiograph after operation.

Minkyu Kim et al: Clear cell odontogenic carcinoma mimicking a cystic lesion: a case of misdiagnosis. J Korean Assoc Oral Maxillofac Surg 2014

of surgery and a $2.4 \times 2.0 \mathrm{~cm}$-sized CCOC with a positive basal resection margin, massive bone marrow infiltration and lymphovascular permeation was reported.(Fig. 6. C, 6. D)

Postoperative radiotherapy was conducted 1 month after surgery. No recurrence or metastasis was detected 10 months after the surgery.(Fig. 8)

\section{Discussion}

Nearly 100 cases of CCOC have been reported in the English-language literature to date, and these tumors have a higher reported incidence in females with an male/female ratio of $1: 1.8$. Most cases of $\mathrm{CCOC}$ have been diagnosed in patients over the age of 40 , with an average age of 54 years. The mandible is more frequently involved than the maxilla, and the posterior of the jaw is a more frequent site than the anterior site ${ }^{9-11}$.

Radiographic findings show mainly radiolucent lesions with or without regular margins, although some cases exhibited a mixed radiolucent-radiopaque lesion. Previous reports have suggested that painless swelling was the most common clinical symptom. In addition, tooth mobility and pain were occasionally associated as symptoms ${ }^{9-11}$.

Approximately one half of patients that were diagnoses with CCOC experienced a recurrence. The likelihood of the recurrence depended on the method of initial therapy and the 
extent of the tumor invasion. Three-quarters of the patients who were treated with conservative care (curettage or enucleation) had recurrence and one-third of the patients who were treated with resection experienced a recurrence. Conservative care (curettage or enucleation) and presence of soft tissue involvement were associated with a higher recurrence rate ${ }^{10,12}$. The ideal treatment approach for CCOC has not been determined. A wide resection with at least $1 \mathrm{~cm}$ of a tumor-free margin is recommended and when there is evidence broad soft tissue invasion, palpable neck lymph node, perineural invasion or tumor removal without free margins, adjuvant neck dissection and/or radiotherapy should be considered ${ }^{10,12,13}$. However, except for squamous cell carcinoma and highgrade central mucoepidermoid carcinoma, neck dissection is rarely required for maxillary carcinomas without nodal metastases $^{12-14}$

In our case, the patient had swelling, incision and drainage history and a well-defined unicystic radiolucent lesion, that was comparable with a cystic lesion. At first we misdiagnosed the lesion as an infected cyst, performed decompression and were unable to send specimen for pathologic examination. Our treatment was limited because we did not make a correct diagnosis when the patient first presented at our clinic. When decompression was performed, the clinical findings were similar to a cystic lesion and during follow the up period we found that lesion size decreased. Currently, mass properties have not been described in previous reports, and our case study presented with both radiographic and clinical similarities to cystic lesion symptoms; for these reasons our diagnosis was delayed. Additional reports have indicated that many cases of CCOC are misdiagnosed because of its rarity and similarity to cystic lesions ${ }^{11,13}$. In this report, we discuss a patient that presented with a painful cystic lesion, jaw enlargement jaw and loosening teeth. Similar cases should be considered for the possibility of malignant CCOC to identify and treat patients with CCOC.

\section{Conflict of Interest}

No potential conflict of interest relevant to this article was reported.

\section{References}

1. Hansen LS, Eversole LR, Green TL, Powell NB. Clear cell odontogenic tumor--a new histologic variant with aggressive potential. Head Neck Surg 1985;8:115-23.

2. Kramer IR, Pindborg JJ, Shear M. Histological typing of odontogenic tumours. Berlin: Springer; 1992.

3. Barnes L. Pathology and genetics of head and neck tumours. Lyon: IARC Press; 2005.

4. Kumar M, Fasanmade A, Barrett AW, Mack G, Newman L, Hyde NC. Metastasising clear cell odontogenic carcinoma: a case report and review of the literature. Oral Oncol 2003;39:190-4.

5. Brinck U, Gunawan B, Schulten HJ, Pinzon W, Fischer U, Füzesi L. Clear-cell odontogenic carcinoma with pulmonary metastases resembling pulmonary meningothelial-like nodules. Virchows Arch 2001;438:412-7.

6. Piattelli A, Sesenna E, Trisi P. Clear cell odontogenic carcinoma. Report of a case with lymph node and pulmonary metastases. Eur J Cancer B Oral Oncol 1994;30B:278-80.

7. Fan J, Kubota E, Imamura H, Shimokama T, Tokunaga O, Katsuki $\mathrm{T}$, et al. Clear cell odontogenic carcinoma. A case report with massive invasion of neighboring organs and lymph node metastasis. Oral Surg Oral Med Oral Pathol 1992;74:768-75.

8. Bang G, Koppang HS, Hansen LS, Gilhuus-Moe O, Aksdal E, Persson PG, et al. Clear cell odontogenic carcinoma: report of three cases with pulmonary and lymph node metastases. J Oral Pathol Med 1989;18:113-8.

9. Swain N, Dhariwal R, Ray JG. Clear cell odontogenic carcinoma of maxilla: A case report and mini review. J Oral Maxillofac Pathol 2013;17:89-94.

10. Zhang J, Liu L, Pan J, Tian X, Tan J, Zhou J, et al. Clear cell odontogenic carcinoma: report of 6 cases and review of the literature. Med Oncol 2011;28(Suppl 1):S626-33.

11. Werle H, Blake FA, Reichelt U, Schmelzle R, Heiland M. Clearcell odontogenic carcinoma: a new case and long-term follow-up of an old case, and review of the literature. J Oral Maxillofac Surg 2009;67:1342-8

12. Ebert CS Jr, Dubin MG, Hart CF, Chalian AA, Shockley WW. Clear cell odontogenic carcinoma: a comprehensive analysis of treatment strategies. Head Neck 2005;27:536-42.

13. Avninder S, Rakheja D, Bhatnagar A. Clear cell odontogenic carcinoma: a diagnostic and therapeutic dilemma. World J Surg Oncol 2006;4:91

14. Chaine A, Pitak-Arnnop P, Dhanuthai K, Bertrand JC, Bertolus C. An asymptomatic radiolucent lesion of the maxilla. Clear cell odontogenic carcinoma. Oral Surg Oral Med Oral Pathol Oral Radiol Endod 2009;107:452-7. 